\title{
Contribution of individual behavioural change on household carbon footprint
}

\author{
Lia Marchi", Vincenzo Vodola, Cristina Visconti, Jacopo Gaspari and Ernesto Antonini \\ Department of Architecture, University of Bologna, 40136 Bologna, Italy
}

\begin{abstract}
Many actions have been undertaken worldwide to cope with climate change and to effectively reach the 2030 Agenda for Sustainable Development. Top-down approaches, based on both policies for the development of enabling technologies and incentives to promote their wide applications, have been largely adopted in most of the cases. However, the potential contribution of changes in individual behaviours still represents an underestimated field of improvement, despite many scholars have already evidenced their considerable expected impacts. This paper presents the first outcomes of a study on the role of citizens' behavioural change in reducing GHG emissions, focussing on the functions and performed activities at household level. Starting from a review of the emerging body of literature on the topic, a map is drafted linking the people's actions and choices and their most relevant effects on each of the environmental categories they can interact with. The mapping provides a list of suitable practices and lifestyles shifts to be adopted, organized by categories and weighted by their emission potential reduction on the whole households' carbon footprint. This results in a sort of easy-to-read console allowing citizens to operate according to more informed decisions within their homes, thus accelerating the sustainable transition by bottom-up initiatives.
\end{abstract}

\section{Introduction}

The reduction of Greenhouse gas (GHG) emissions still remains one of the primary goals of climate-change mitigation policies at global, national and regional levels, with the aim of redirecting towards this purpose both the economic and productive systems, including strategic sectors such as industry, transportation, agriculture and construction, as well as the management of the involved resources (energy, water, materials).

The built environment accounts for three main GHG emitters: energy, transportation and buildings [1,2], while the most relevant share of energy related GHG emissions is that generated by commercial and residential buildings [2].

The huge changes required to shift GHG emissions trends are usually considered under the umbrella of governmental policies at the macro scale. So far the effects of the shifts that can be performed at individual or community household levels have been instead largely overlooked, despite emerging as a fundamental factor in achieving long-term $\mathrm{CO}_{2}$ reduction goals [3].

*Corresponding author: lia.marchi3@unibo.it 
As the carbon footprint has become widely used as an impact indicator, the effects of individual and collective contributions became more evident and the combined relevance of both elements entered the debate on actions against the threat of global climate change [4]. According to these premises, this paper assumes carbon footprint - generally defined as equal to the greenhouse gas emissions generated by a person, organization or product (Johnson $2008)$ - as an equivalent indicator of $\mathrm{CO}_{2}$ emission, to be gauged in terms of global warming potential (GWP) [5, 6].

\subsection{Contribution of households to climate change}

Whereas the consumption-related emissions are often higher than the production-related ones, households are accountable for nearly three quarters of global carbon emissions [7]. Food, transports and housing are the main generators of household emissions, which are depending on multiple variables, as the household size, rural/urban environment, diet, energy supply, leisure habits, as well as the income level [7-9]. Household carbon footprint includes two types of emissions: a) direct emissions related to direct energy use in the houses (such as fuels for heating, electricity) and to fossil fuels for transportation; b) indirect or embodied emissions across flows production as supply chain emissions (i.e. appliances and furniture used in the house) $[6,7]$. These are about $60-70 \%$ of the carbon footprints of Western households [7].

Buildings produce $8.3 \mathrm{Gt} \mathrm{CO}_{2}$ e per year, being responsible for about $18 \%$ of global GHG emissions, which rises to more than $30 \%$ in many developing nations. The emissions deriving from the primary energy consumption of buildings are estimated at $3.5 \mathrm{Gt} \mathrm{CO}_{2} \mathrm{e}$ per year, corresponding to about $8 \%$ of GHG emissions. Residential buildings account for $62 \%$ of total emissions [10]. Within this boundary, household carbon emissions have been recognized as one of the most important contributors to climate change, with a significant impact on both the local and global environment, thus with large room for improvement and a strong mitigation potential [11].

All household emissions can be related to consumers' behaviours, although with different effects and intensity according to the specific contexts and related actions which generate them. The behavioural changes to reduce the household propelled global warming are spanning over the three domains of food, transport and housing, and include among others: reducing of meat and dairy intake and avoiding food waste; increasing the use of public transport and zero-emission transport means; adopting energy-efficient appliances and devices, limiting HVAC use by lowering the required set-point levels [12].

\subsection{Citizens behavioural change and expected GHG abatement potential}

A long-standing discussion has taken hold as to whether behavioural actions can reduce the contribution of households in climate change. In their meta-analysis, testing behavioural interventions to promote household action on climate change, Nisa et al. [13] argue that behavioural interventions, taken alone, have very little effect on household actions. In response, Stern [14] points out that a long-standing body of multi-method research demonstrates that behavioural interventions can greatly increase the impact of household actions when combined with non-behavioural ones.

In the scientific literature, behavioural actions are broadly defined as interventions that do not include regulations or financial incentives. Consequently, behavioural change is usually referred to as an "active effort in changing nature or in some cases the amount of consumption" [15]: which means pro-environmental behaviours can address either a quantitative change in an individual lifestyle, or a qualitative shift (from reduction to replacement). Moreover, a clear distinction could be added between "frequently occurring 
behaviours (i.e. travel to work, adjusting room temperatures, changing diet) whose effects must be aggregated through multiple repetitions, and infrequent behaviours, usually involving investments, whose effects are almost fully achieved by a single action (i.e. upgrading the energy efficiency of the building envelope, adopting more energy-efficient home power systems and vehicles" [14].

International climate policy debate has been focused on technology and incentives as means, too often relegating behavioural change to an afterthought [15], whilst citizens behaviour change can make a significant difference if adopted on a collective basis [3]. Hence a tighter collaboration between the two "dimensions" of policymakers and society is needed. Some recent studies show in fact that citizens behavioural change can lead to significant reduction in emissions [16]. Accordingly, behavioural insights have been increasingly included in environmental policies worldwide [17].

Faber [16] shows how the reduction of $1{ }^{\circ} \mathrm{C}$ in house heating was estimated to save up to $22 \mathrm{Mt} \mathrm{CO}_{2}$ in 2020, while a shift to vegetarian diet would have saved more than $250 \mathrm{Mt} \mathrm{CO}_{2}$. Similarly, a study by McKinsey [10] shows behaviour change can contribute to GHG emission reduction between 3.5 and 5.0 $\mathrm{Gt} \mathrm{CO}_{2}$ e per year in 2030, but there is a high degree of uncertainty in the estimates as it largely depends on effective incentives established by policy makers. In practical terms, according to Niamir [18], behavioural change alone can contribute to $4-8 \%$ of overall $\mathrm{CO}_{2}$ emission reduction. Similarly, a report by Williamson [3] estimates plausible and optimum scenarios of behavioural solution contribution to reduce emissions by $2030-50$, respectively of about $20 \%$ and $37 \%$ : in the plausible scenario - which considers safety factors - agriculture and land management domain accounts for about $40 \%$; energy and material (13\%), food (39\%) and transport (8\%).

Food, mobility and housing are generally the most important categories in the investigation on consumer behaviour and GHG emissions, followed by waste management $[16,19]$. That means a change in individual attitude within one of this field can produce significant reduction of impact if adopted on a collective basis.

Data on household carbon footprint varies a lot depending on socio-economic (i.e. income, urban-rural, household size), geographic and technical factors [9] and are especially available for wealthiest countries, where consumption and accordingly emissions are higher. According to Nature's carbon footprint calculator [20] the average carbon footprint for a person in the United States is 16 tons of $\mathrm{CO}_{2}$, one of the highest rates in the world. Globally the average is closer to 4 tons. Eurostat estimated the EU's total carbon footprint was equal to 7 tons of $\mathrm{CO}_{2}$ per person in 2018, however, Ivanova [9] founds a significant difference within EU regions, between 0.6 and 6.5 tons of $\mathrm{CO}_{2} \mathrm{e} / \mathrm{cap}$.

The great variety of data and indicators used to describe the mitigation potential of carbon emission due to lifestyles change suggests there is the need for a systematic observation to provide citizens comparable data and figures. This could help citizens to take informed decisions within their homes and raise their awareness level about the role and the impact of their actions (from daily routines to one-shot investments).

\section{Methodology}

This paper explores which interventions are effective in supporting climate change mitigation by individuals and households starting from the identification of the environmental categories which are generally considered for carbon footprint calculations. Hence an investigation in some of the principal environmental related institutions and policies at EU level and beyond has been performed to identify a comprehensive and widely shared set of environmental categories. A great variety of categories has been found in Green Deal objectives; European Environmental Agencies reports; Intergovernmental Panel on Climate Change web page; BRE Group website. From this, a simplified environmental matrix of categories relevant to 
households has been retrieved to structure the investigation in a user-friendly perspective (i.e. easy-to-understand for non-technicians) and also to be more adherent with categories used in many carbon footprint calculators on the web (i.e., ActNow; WWF; US EPA; Nature).

Then, the methodology is broken down into three main steps:

1. Detecting the typical weights of each environmental category on the whole household carbon footprint.

2. Mapping recurrent behavioural changes and their expected effects in terms of potential carbon emission reduction, by literature search but also by calculating their effect on different household carbon footprint scenarios.

3. Designing a dashboard by which citizens can identify the effects of practices they can adopt within their home, so helping them in making appropriate decisions.

The first step consists in a literature search in scientific databases to find data and figures on the average weight each category assumes on the whole household carbon footprint. Furthermore, recurrent impacts per category are detected and described. Accordingly, the second step expands the search into a mapping - for each category - of frequently mentioned behavioural change and practices that citizens can adopt to reduce their overall environmental impact (thus reducing the household carbon footprint). Retrieved practices are organized according to environmental category and described with data and facts percentage on their $\mathrm{CO}_{2}$ equivalent abatement potential. Hence the practices that are considered variables in a selected open access carbon footprint calculator are used to evaluate their relative contribution to reduce the household carbon footprint. Lastly, based on the assumption that citizens need to reach a certain level of knowledge and awareness before seriously considering a change in their lifestyles and behaviours [18], a dashboard has been designed aiming to make households aware of their baseline carbon footprint, and hopefully to push them in reducing their impact by adopting behavioural changes whose effect is shown in the resulting carbon footprint (third step). This led to prioritizing behavioural change based on their GHG abatement potential generating a tool that individuals can use to check the effects of their actions on their household carbon footprint.

\section{Results}

\subsection{Environmental categories and their relevance on household carbon footprint}

The proposed environmental categories included in the matrix are: Air, Water, Food \& Waste and Energy. Although the relative weights these assume on the whole carbon footprint can vary, some average data can be derived from the literature. According to Ivanova [9] in EU air pollution due to transport emissions is the largest contributor to household carbon footprint, accounting for around $25 \%$ of the total share; followed by food (18\%). Similarly, in the US, Druckman [7] identifies transport emission, food and home energy as the most impacting categories. On this basis, recurrent impacts found in literature for each category can be listed as follows:

Air - Principal citizens' activities that affect the quality of local air at household level are house heating and private transport [19], which are still largely dependent on fossil fuels (around $80 \%$ of global energy and $66 \%$ of electrical generation) [21]. The transport sector is almost completely dependent on fossil fuels, producing approximately $25 \%$ of all energyrelated carbon dioxide emissions [22].

Water - Major impacts in this category are due to water consumption for hygiene purposes and garden watering. Individual water consumption generally decreases with the increase of 
family size, and adolescents and twenties consume on average more than $70 \%$ for a shower than elders [17, 23].

Food \& Waste - Recycling, reusing and waste reducing patterns affect the final impact of households. Municipal wastes are still a great issue due to the great variety of wastes produced and low recycling rate, especially by adults. In parallel, diet and food habits highly affect the household carbon footprint, where for example diets highly based on meat or exotic fruits are important contributors.

Energy - Residential heating is generally the most accountable rate $(64 \%)$ in household energy demand, followed by $15 \%$ for water heating; $14 \%$ lighting and appliances; $6 \%$ cooking [24].

\subsection{Set of behavioural change and their expected effects.}

The outcomes of the performed review are summarized in table 1 that provides an overview of proposed actions and behavioural change found in literature for each environmental category, along with their expected effect.

Table 1. Extract of retrieved behaviours to reduce household carbon footprint, divided per categories.

\begin{tabular}{|c|c|}
\hline \multicolumn{2}{|l|}{ Air } \\
\hline Using mass transit & 6.6-26.3 Gt $\mathrm{CO}_{2} \mathrm{e}$ (Williamson, 2018) \\
\hline Changing car into a smaller one & $35 \mathrm{Mt} \mathrm{CO}_{2}$ in 2050 (Faber, 2012) \\
\hline Using electric vehicles & 10.8-52.4 Gt $\mathrm{CO}_{2} \mathrm{e}$ (Williamson, 2018) \\
\hline Installing rooftop photovoltaic & 24.6-40.3 $\mathrm{Gt} \mathrm{CO}_{2} \mathrm{e}$ (Williamson, 2018) \\
\hline \multicolumn{2}{|l|}{ Water } \\
\hline Reducing time for shower & $\begin{array}{l}23 \% \text { reduction in water use by reducing } 20 \% \text { the } \\
\text { duration of shower thanks to water metering (OECD, } \\
2017 \text { ) }\end{array}$ \\
\hline Installing water saving devices & 4.6-6.3 $\mathrm{Gt} \mathrm{CO}_{2} \mathrm{e}$ (Williamson, 2018) \\
\hline \multicolumn{2}{|l|}{ Food \& Waste } \\
\hline Recycling materials and paper & $\begin{array}{l}\text { 3.7-5.5 } \mathrm{Gt} \mathrm{CO}_{2} \mathrm{e} \text { (Williamson, 2018); recycling } \\
\text { average daily plastic waste can save every day } 300 \\
\text { grams of } \mathrm{CO}_{2} \text { emissions (ActNow) }\end{array}$ \\
\hline Reducing meat-based meals & $\begin{array}{l}\text { vegetarian } 66.1-87.0 \mathrm{Gt} \mathrm{CO}_{2} \mathrm{e} \text { (Williamson, 2018); } \\
\text { one animal protein-free day per week } 50 \mathrm{Mt} \mathrm{CO}_{2} \\
\text { (Faber, 2012) }\end{array}$ \\
\hline Reducing food waste & 70.7-93.7 $\mathrm{Gt} \mathrm{CO}_{2} \mathrm{e}$ (Williamson, 2018) \\
\hline Composting instead of landfill sending & 2.3-3.6 Gt $\mathrm{CO}_{2} \mathrm{e}$ (Williamson, 2018) \\
\hline \multicolumn{2}{|l|}{ Energy } \\
\hline LED lighting & $\begin{array}{l}\text { 7.8-8.7 } \mathrm{Gt} \mathrm{CO}_{2} \mathrm{e} \text { (Williamson, 2018); } 670 \mathrm{Mt} \mathrm{CO}_{2} \mathrm{e} \\
\text { per year (McKinsey, 2009) }\end{array}$ \\
\hline Reducing indoor temperature $\left(-1^{\circ} \mathrm{C} ;-2^{\circ} \mathrm{C}\right)$ & $22 \mathrm{Mt} \mathrm{CO}_{2} ; 45 \mathrm{Mt} \mathrm{CO}_{2}$ (Faber, 2012) \\
\hline $\begin{array}{l}\text { Installing smart thermostats or optimising } \\
\text { the setting }\end{array}$ & $\begin{array}{l}\text { 2.6-5.8 } \mathrm{Gt} \mathrm{CO}_{2} \mathrm{e} \text { (Williamson, 2018); } 11 \mathrm{Mt} \mathrm{CO}_{2} \\
\text { (Faber, 2012) }\end{array}$ \\
\hline $\begin{array}{l}\text { Adopting methane digester (biogas from } \\
\text { organic waste) }\end{array}$ & 1.9-9.8 $\mathrm{Gt} \mathrm{CO}_{2} \mathrm{e}$ (Williamson, 2018) \\
\hline Optimising ventilation behaviour & $43 \mathrm{Mt} \mathrm{CO}_{2}$ (Faber, 2012) \\
\hline
\end{tabular}




\begin{tabular}{|c|c|}
\hline Installing solar panel for water heating & 6.1-17.7 Gt $\mathrm{CO}_{2} \mathrm{e}$ (Williamson, 2018) \\
\hline $\begin{array}{l}\text { Installing efficient appliances and } \\
\text { electronics }\end{array}$ & $\begin{array}{l}550 \mathrm{Mt} \mathrm{CO}_{2} \mathrm{e} \text { per year (saving ab. 35\%) (McKinsey, } \\
2009 \text { ) }\end{array}$ \\
\hline Unplugging appliances when not in use & $\begin{array}{l}\text { save more than } 3.5 \mathrm{kWh} \text { of electricity and about } 1.5 \\
\mathrm{~kg} \text { of } \mathrm{CO}_{2} \text { emissions (UN ActNow) }\end{array}$ \\
\hline Turn off lights when leaving the room & $\begin{array}{l}\text { turn a 60kW light bulb off for } 4 \text { hours, save } 0.24 \\
\text { kWh of electricity and about } 100 \text { grams of } \mathrm{CO}_{2} \\
\text { emissions (UN ActNow) }\end{array}$ \\
\hline
\end{tabular}

Since detected actions and practices refer to multiple units and time range, not directly comparable, a first trial of normalization has been performed to provide comparable and easy to visualize data. A household carbon footprint scenario 0 has been calculated using UN Act Now footprint calculator - which is an open access tool that everyone can use in a very simple way. The following input data (corresponding to a quite recurrent situation in Italy ${ }^{1}$ ) were used:

- 3 family components, resident in Italy

- $\quad$ size and type of housing: $100 \mathrm{~m}^{2}$; detached house

- $\quad$ energy consumption: $350 \mathrm{kWh} /$ month ( $0 \%$ from renewable sources; $100 \%$ from natural gas)

- transport: walking/cycling per 5 hours/week; two cars (one diesel with $15.000 \mathrm{~km} / \mathrm{year}$ and average consumption $51 / 100 \mathrm{~km}$; the other gasoline with $15.000 \mathrm{~km} /$ year and average consumption $51 / 100 \mathrm{~km}$ ) and 4 short range flights per year.

- food: meat in some meals; not buying local food; twice a week at restaurant; recycling plastic, tin and glass.

The resulting annual household footprint is 24.69 tons of $\mathrm{CO}_{2} \mathrm{e}$ (world average is 14.01). The $51 \%$ of which is due to the lifestyle (food, waste and water categories); the $17 \%$ to energy and the remaining to transport (air category). On this basis, practices from Table 1 which are assumed as variables of the selected calculator have been identified and their contribution to reduce footprint have been calculated. Table 2 reports the result of this activity, where one variable per scenario is changed.

\begin{tabular}{|l|l|l|}
\hline Actions & $\begin{array}{l}\text { Carbon Footprint } \\
{\left[\text { tons of } \mathrm{CO}_{2} \mathrm{e}\right]}\end{array}$ & $\begin{array}{l}\text { Abatement } \\
\text { potential }\end{array}$ \\
\hline 0. Baseline scenario & 24.69 & - \\
\hline $\begin{array}{l}\text { 1. Using mass transport (eliminating diesel car and } \\
\text { adding 10 hours per week by city bus) }\end{array}$ & 23.63 & $-1.06(-4,30 \%)$ \\
\hline $\begin{array}{l}\text { 2. Installing Rooftop photovoltaic (30\% of energy } \\
\text { consumption) }\end{array}$ & 24.08 & $-0.61(-2.47 \%)$ \\
\hline 3. Recycling materials and paper & 24.67 & $-0.02(-0.08 \%)$ \\
\hline 4. Reducing meat-based meals & 22.89 & $-1.80(-7.29 \%)$ \\
\hline 5. Composting instead that sending to landfill & 24.60 & $-0.09(-0,36 \%)$ \\
\hline
\end{tabular}

\footnotetext{
${ }^{1}$ According to ISTAT in Italy about one third of households consists of a couple with one child (https://www.istat.it/en/population-and-households?data-and-indicators).
} 


\subsection{Dashboard as support to household's decision making}

The list of actions, whose extract is summarised in Table 2, feeds a dashboard that simulates the effect of behavioural change on household carbon footprint.

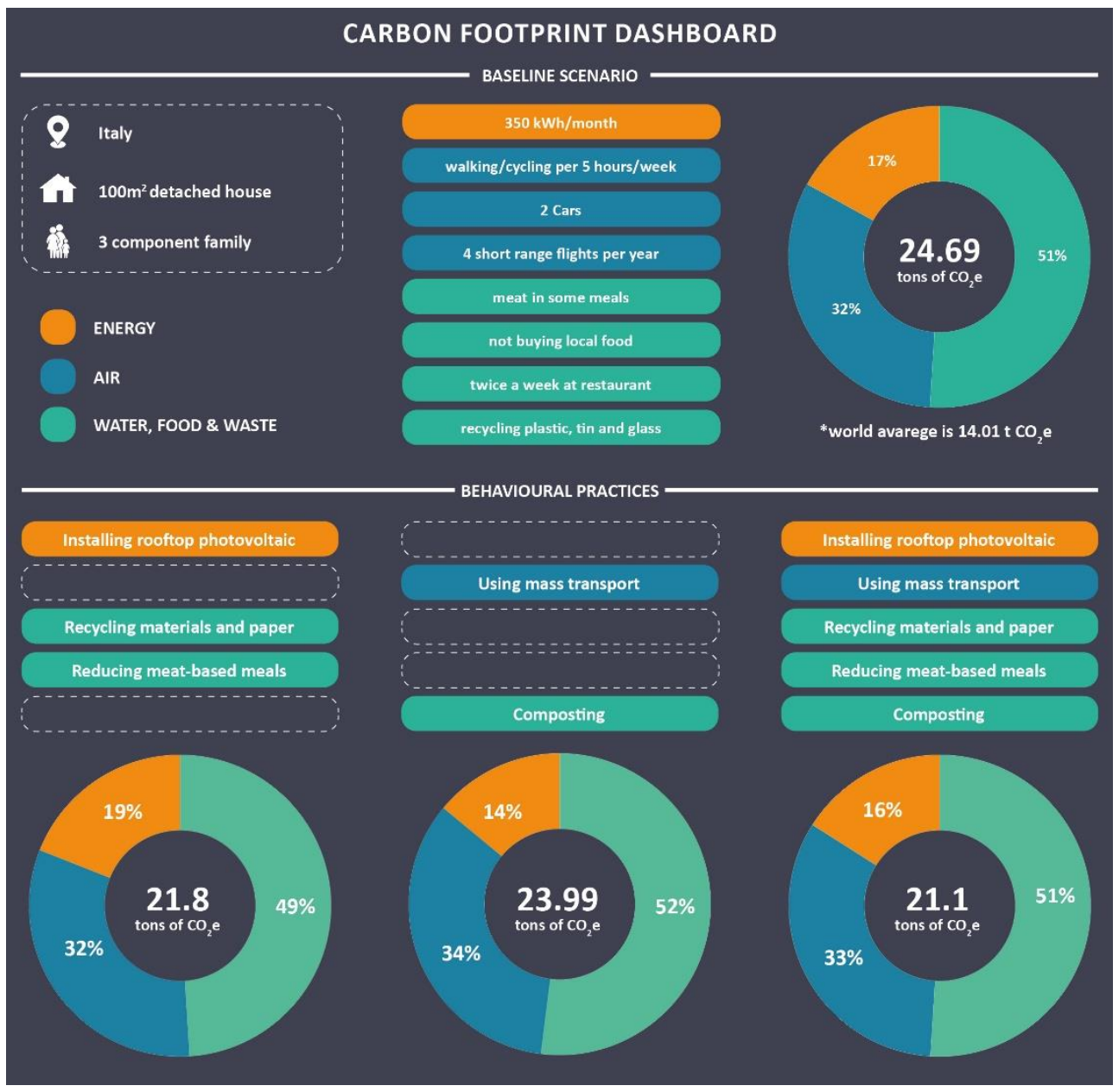

Fig. 1. Carbon Footprint Dashboard layout.

Figure 1 provides a conceptual scheme of the dashboard, where the consultation mode (or sequence of actions) by end users is reflected:

- starting conditions of household data, such as number of family components, housing size, location can be easily filled and then the user should select and quantify her/his household 
average impacts (i.e. energy consumption; food habits; recycling rates) per each environmental category;

- the baseline household carbon footprint is thus returned on an annual basis, and relative weight of each category is provided, along with an average household carbon footprint at national level (which can act as useful mean of social comparison to stimulate the change);

- the user is then invited to select and quantify one or more actions due to her/his households components behavioural change (i.e. reducing average time for showering of 5 minutes per time);

- an updated carbon footprint can be visualised in real time displaying the effect of the proposed changes.

In the bottom part of Figure 1 three scenarios of possible final output are simulated, where different combinations of actions from Table 2 are proposed. In particular: scenario 1 combines actions 1, 3 and 4; scenario 2 combines actions 2 and 5; scenario 3 combines all the five proposed actions.

\section{Discussion and Conclusions}

From the literature search of practices and their mitigation potential emerges a great variety and differences in methods, unity of measurement and thresholds. This uncertain way of communicating the key criteria and concepts raises the risk of reducing the citizens' level of understanding and interest in joining the transition process and may reduce the adoption of pro-environmental behaviour, or rather generate misunderstandings on real impact versus people's perception. Impact knowledge is recognized as an essential step in raising one's own consciousness and, as a result, considering improving attitudes and behaviours.

This study is the initial stage of a research aiming to work with data according to a more comparable approach, providing citizens with user-friendly tools to be aware and quantify the effect of their behaviours and lifestyles choices.

To this purpose the study:

- investigated recurrent actions and behavioural changes along with their expected mitigation potentials, providing a first list of practices organized within a structured system vision per environmental categories.

- devised a dashboard as a useful tool to raise citizens' awareness on their actual impacts, using a diffused mean as a web-based carbon footprint calculator and integrating it a set of "buttons" (behaviours) to select and quickly visualize their effects.

Further development of the research could expand the investigation of behaviours and their reduction potential on the household carbon footprint, expanding the list in Table 1 . The relative weight of other actions in addition to those proposed in Table 2 can be explored by using other calculators which express them as variables.

Considering that household carbon footprint largely includes embodied emissions (60$70 \%$ ) related to supply chain and goods used in households, a more direct knowledge on hidden $\mathrm{CO}_{2}$ emissions and related behavioural changes is needed.

More aware consumption models (particularly with reference to food habits and goods) are claimed as necessary to rebalance unsustainable pathways beyond a solely decreasing of energy use or less impacting transportation. Even though the importance of addressing more efficient and sustainable systems for food provision, transportation and urban stock regeneration still represent a priority, the study of adequate measures to address behavioural and lifestyles changes can be considered a valuable and unavoidable tool to significantly contribute in GHGs reduction of households' footprint in several countries. 


\section{References}

1. A.V. Fenner, C.J. Kibert, J. Woo, S. Morque, M. Razkenari, H. Hakim, X. Lu, Ren. Sust. En. Rev., 94, 1142-1152 (2008).

2. EPA, Inventory of U.S. greenhouse gas emissions and sinks: 1990-2016, EPA 430-P18-001 (2018).

3. K. Williamson, A. Satre-Meloy, K. Velasco, K. Green, Climate Change Needs Behavior Change: Making the Case For Behavioral Solutions to Reduce Global Warming, Rare (2018).

4. G. Stankuniene, D. Streimikiene, G. L. Kyriakopoulos, Sustainability, 12, 7369 (2020).

5. E. Johnson, Energy Policy, 36, 1569-1573 (2008).

6. M. Christis, K. Breemersch, A. Vercalsteren, E. Dils, J. Clean. Prod., 228, 1167-1175 (2019).

7. A. Druckman, T. Jackson, in Taking Stock of Industrial Ecology, 181-204 (2016).

8. M. Buchs, S. V. Schnepf, Ecological Economics, 90, 114-123 (2013).

9. D. Ivanova et al., Environ. Res. Lett., 12, 054013 (2017).

10. McKinsey \& Company, Pathways to a Low-Carbon Economy. Version 2 of the global greenhouse gas abatement cost curve (2009).

11. P. Nejat, F. Jomehzadeh, M. M. Taheri, M.Z. Majid, Ren. Sust. En. Rev., 43, 843-862, (2015)

12. IPCC, Special Report on Global Warming of $1.5^{\circ} \mathrm{C}$ (2018).

13. C.F. Nisa, J.J. Bélanger, B.M. Schumpe, et al., Nat Commun 10, 4545 (2019).

14. P.C. Stern, Nat Commun 11, 918 (2020).

15. G. Dubois, B. Sovacool, C. Aall, M. Nilsson, C. Barbier, et al., Energy Res. Soc. Sci. 52, 144 (2019)

16. J. Faber et al, Behavioural Climate Change Mitigation Options and Their Appropriate Inclusion in Quantitative Longer Term Policy Scenarios - Main Report, Delft, CE Delft, April 2012

17. OECD, Tackling Environmental Problems with the Help of Behavioural Insights, OECD Publishing, Paris (2017).

18. L. Niamir, G. Kiesewetter, F. Wagner, et al., Clim. Change 158, 141 (2020).

19. A. Carducci, G. Donzelli, L. Cioni, G. Palomba, M. Verani, et al. Epidemiology Biostatistics and Public Health 14, 1 (2017).

20. Nature Carbon Footprint Calculator - https://www.nature.org/en-us/get-involved/howto-help/carbon-footprint-calculator/

21. ActNow UN Campaign: https://www.un.org/sustainabledevelopment/wpcontent/uploads/2021/02/ActNow-action-guide.pdf

22. IPCC, 2014: Climate Change 2014: Mitigation of Climate Change. Contribution of Working Group III to the Fifth Assessment Report of the Intergovernmental Panel on Climate Change, Cambridge University Press, Cambridge, United Kingdom and New York, NY, USA

23. S.H.A. Koop, A.J. Van Dorssen, S. Brouwer, J. Environmental Management 247, 867 (2019)

24. Eurostat, 'Greenhouse gas emission statistics - air emissions accounts.', 2021. 